\title{
Effects of the Veterinary Pharmaceutical Ivermectin in Indoor Aquatic Microcosms
}

\author{
Harry Boonstra • Erik P. Reichman • \\ Paul J. van den Brink
}

Received: 6 January 2010/Accepted: 5 April 2010/Published online: 27 April 2010

(c) The Author(s) 2010. This article is published with open access at Springerlink.com

\begin{abstract}
The effects of the parasiticide ivermectin were assessed in plankton-dominated indoor microcosms. Ivermectin was applied once at concentrations of 30, 100, 300, 1000, 3000, and 10,000 ng/l. The half-life (dissipation time $50 \% ; \mathrm{DT}_{50}$ ) of ivermectin in the water phase ranged from 1.1 to 8.3 days. The lowest NOEC $_{\text {community }}$ that could be derived on an isolated sampling from the microcosm study by means of multivariate techniques was $100 \mathrm{ng} / \mathrm{l}$. The most sensitive species in the microcosm study were the cladocerans Ceriodaphnia sp. (no observed effect concentration, NOEC $=30 \mathrm{ng} / \mathrm{l}$ ) and Chydorus sphaericus $(\mathrm{NOEC}=100 \mathrm{ng} / \mathrm{l})$. The amphipod Gammarus pulex was less sensitive to ivermectin, showing consistent statistically significant reductions at the 1000-ng/l treatment level. Copepoda taxa decreased directly after application of ivermectin in the highest treatment but had already recovered at day 20 posttreatment. Indirect effects (e.g., increase of rotifers, increased primary production) were observed at the highest treatment level starting only on day 13 of the exposure phase. Cladocera showed the highest sensitivity to ivermectin in both standard laboratory toxicity tests as well as in the microcosm study. This study demonstrates that simple plankton-dominated test systems for assessing the effects of ivermectin can produce results
\end{abstract}

\footnotetext{
H. Boonstra · P. J. van den Brink

Alterra, Department for Water and Climate,

Wageningen University and Research Centre,

PO Box 47, 6700 AA Wageningen, The Netherlands

E. P. Reichman · P. J. van den Brink ( $\square)$

Wageningen University, Department of Aquatic Ecology and Water Quality Management, Wageningen University and Research Centre, PO Box 47, 6700 AA Wageningen, The Netherlands

e-mail: paul.vandenbrink@wur.nl
}

similar to those obtained with large complex outdoor systems.

Until recently, exposure to human and veterinary pharmaceuticals in the environment has received little attention, and little is known about the ecotoxicological effects of these pharmaceuticals in the environment (Fent et al. 2006). After use, they are (partly) excreted by humans or animals through urine or feces and can then enter the environment via the sewage treatment plant or, in the case of animals, by reaching the surface water directly through excretion on the field (Halling-Sørensen et al. 1998). Although most pharmaceuticals have relatively short halflives and can be degraded by biotic and abiotic processes, exposures might be chronic because of continual release (Halling-Sørensen et al. 1998). Measured concentrations of individual pharmaceuticals are generally low in surface waters, ranging from nanograms per liter to micrograms per liter (Halling-Sørensen et al. 1998; Kolpin et al. 2002), and effect data generated from laboratory and semifield studies (e.g., cosm studies) can be used to evaluate the risks these contaminants pose (Van den Brink et al. 2005).

Indoor microcosms are able to fill the gap between laboratory tests and more costly outdoor cosm and field studies. They could, for example, be used to verify risk assessments based on acute data generated with short-term laboratory tests. Conversely, comparing results from indoor studies with those from outdoor studies to determine whether the less costly and less laborious indoor studies yield the same results creates a basis for the evaluation of the ecotoxicological significance of veterinary pharmaceutical compounds (in this case, ivermectin). This is consistent with the recommendations of the Higher-tier Aquatic Risk Assessment for Pesticides (HARAP) 
workshop for the development of reliable, validated, and cost-effective smaller test systems (Campbell et al. 1999). It would allow smaller model ecosystems (e.g., microcosms that are easier to replicate and manipulate) for specific questions to replace mesocosms. Microcosms are, furthermore, more useful than larger systems in elucidating the chain of events after chemical stress (Leeuwangh et al. 1994). In addition, in microcosms that contain a simple community, the indirect effects of toxicants might be more pronounced than in mesocosms with a more complex food web.

This article thus focuses on the results of a relatively short-term indoor (48 days) microcosm experiment under semirealistic conditions. Both short- and long-term results could be determined from this microcosm study. The findings were compared to the outcome of laboratory tests and outdoor cosm studies. The experiments were performed with ivermectin as well as other avermectins, both because of the scale of their present use and because sufficient data are available from previous studies to test the accuracy of the microcosm model.

In the European Union, 194 ton (extrapolated data) of antiparasitic veterinary pharmaceuticals were used in 2004 (Kools et al. 2008). Of these, ivermectin has (since 1981) been one of the most widely used; it is used to treat and control internal and external parasites in cattle, horses, and sheep (Campbell et al. 1983). It has the pharmacological profile of an anxiolytic drug with GABAergic properties. GABA is an inhibitory neurotransmitter that regulates the excitability of virtually all of the neurons in the brain and has been implicated in physiological and pathophysiological events underlying brain function and/or dysfunction (Spinosa et al. 2002). The anthelmintic and insecticidal property of ivermectin is caused by potentiating and agonistic activity on glutamate-gated $\mathrm{Cl}^{-}$channels (Adelsberger et al. 1997).

Acute tests have indicated that ivermectin in the environment is highly toxic (Boxall et al. 2004; Edwards et al. 2001). In freshwater acute tests based on immobility, the most sensitive species tested was Daphnia magna, with a 48-h LC $_{50}$ ranging from 5.7 to $25 \mathrm{ng} / \mathrm{l}$ (Garric et al. 2007; Halley et al. 1989). Recent investigations of chronic effects of ivermectin on freshwater invertebrates in the laboratory and in aquatic cosms (Garric et al. 2007; Sanderson et al. 2007) showed chronic effects at (very) low concentrations of $0.001 \mathrm{ng} / \mathrm{l}$ for adult-size D. magna (Garric et al. 2007; Lopes et al. 2009) and $30 \mathrm{ng} / \mathrm{l}$ for ecosystem structure and functioning (Sanderson et al. 2007). All of these findings are based on laboratory and long-lasting outdoor mesocosms studies [more natural, semirealistic systems with natural combinations of organisms and abiotic conditions (Van den Brink et al. 2005)] but had not yet been verified in indoor microcosms, as is done here.

\section{Materials and Methods}

\section{Experimental Setup}

The study was performed using 16 microcosms situated in a water bath for temperature regulation in a climate-controlled room (Van Wijngaarden et al. 2005). Each microcosm consisted of a full-glass cylinder (diameter, $25 \mathrm{~cm}$; height, $38 \mathrm{~cm}$; volume $18 \mathrm{l}$ ) with a sediment layer of $\sim 2.5 \mathrm{~cm}$. Sediment and water were collected from an uncontaminated ditch at the Sinderhoeve Experimental Station (Renkum, The Netherlands), as were phytoplankton, zooplankton, and Asellus aquaticus. Gammarus pulex was collected from the Heelsumse Beek (Heelsum, The Netherlands). Plankton was concentrated using a plankton net (mesh size, $55 \mu \mathrm{m}$; Hydrobios, Kiel) and equally distributed $(500 \mathrm{ml})$ over the microcosms. Additionally, the microcosms were inoculated with $D$. magna originating from laboratory cultures (Wageningen University, The Netherlands). To stimulate phytoplankton growth, nutrients $\left(\mathrm{NH}_{4} \mathrm{NO}_{3}\right.$ and $\left.\mathrm{KH}_{2} \mathrm{PO}_{4}\right)$ were added to the microcosms twice a week to achieve concentrations of $0.015 \mathrm{mg} / \mathrm{l}$ of $\mathrm{P}$ and $0.09 \mathrm{mg} / \mathrm{l}$ of $\mathrm{N}$. To control periphyton growth, five snails [Lymnaea stagnalis, (sub)adults] per system were introduced. The microcosms simulated a simple planktondominated nutrient-rich system.

\section{Test System Conditions}

A light regime of $\sim 176 \mu \mathrm{E} / \mathrm{m}^{2} / \mathrm{s}$ for $14 \mathrm{~h}$ per day was provided (Philips IP-55 fittings, with Philips HPI-T 400WE 40, high-pressure metal halide lamps). During the experiment, no other light sources were used. Light intensity was measured by means of a light meter (Li.COR Li-250). Water bath temperatures fluctuated between 20 and $22^{\circ} \mathrm{C}$. To prevent growth of a bacterial layer on the water surface of the microcosms and to stimulate some water movement, compressed air was used to provide a light airflow over the water surface. Water losses due to evaporation were replenished with demineralized water. The water level in the water bath was kept constant with demineralised water as well.

Ivermectin Application and Analysis

Ivermectin was applied to the microcosms once on August 23,2006 as the formulated product Ivomec ${ }^{\circledR}$. To simulate a realistic worst-case environmental exposure, treatment solutions were poured evenly over the water surface while gently stirring the water with a glass rod to promote even distribution throughout the water column. This resulted in as little disturbance of the sediment as possible. The control microcosms received only water, which was similarly 
gently stirred. Treatments comprised 0 (control), 30, 100, $300,1000,3000$, and $10,000 \mathrm{ng} / \mathrm{l}$ of the active substance. Controls were in fourfold and all other treatments were in duplicate. Concentrations of ivermectin in the water were determined $3 \mathrm{~h}, 1$ day, 2 days, 7 days, 14 days, 28 days, and 42 days after application of the test substance.

Depth-integrated water samples $(\sim 100 \mathrm{ml})$ were taken from the microcosms by means of a glass pipette. The exact volume sampled was determined based on weight of the sample. Directly after weighing, solid-phase extraction was performed using Waters Oasis hydrophile-lipophile balance (HLB) 3-ml cartridges (Waters Corporation, Milford, MA). These cartridges were activated by adding 1 vol $(3 \mathrm{ml})$ of methanol and 2 vols $(6 \mathrm{ml})$ of high-performance liquid chromatography (HPLC) water. Water samples of known volume were transferred into the cartridges, and after washing off the cartridges with $3 \mathrm{ml}$ of HPLC water, the samples were eluted into $10 \mathrm{ml}$ glass test tubes by adding $3 \mathrm{ml}$ of acetonitrile. The eluate was evaporated at $40^{\circ} \mathrm{C}$ in a water bath under a gentle stream of nitrogen. Dried samples were derivatized with $100 \mu \mathrm{l}$ of $N$-methylimidazole in acetonitrile $(1: 1 \mathrm{v} / \mathrm{v})$ and $150 \mu \mathrm{l}$ of trifluroacetic anhydride in acetonitrile $(1: 2 \mathrm{v} / \mathrm{v})$. The derivatized samples were transferred to vials containing a polypropylene insert and stored in the refrigerator at $4^{\circ} \mathrm{C}$. The samples were analyzed via HPLC using a Gyncotek M300 high-precision pump, a Gyncotek M480 high-precision pump, a Spark Holland Prospect online sample preparation unit, a Spark Holland Marathon autosampler, a Spark Holland Mistral column oven, and a Jasco FP920 fluorescence detector. Data were acquired with a Thermo Atlas instrument manager.

The mobile phase (water:acetonitril:tetrahydrofuran, 22:38:40 v/v/v) was set at a flow of $1 \mathrm{ml} / \mathrm{min}$. A Vydac $201 \mathrm{TP}$ C18 column $(250 \times 4.6 \mathrm{~mm}, 5 \mu \mathrm{m})$ was used. The column temperature was adjusted to $25^{\circ} \mathrm{C}$. The injected volume of the sample was $20 \mu \mathrm{l}$. The used excitation and emission wavelength were 365 and $475 \mathrm{~nm}$ (Kitzman et al. 2006). The limit of detection (LOD) and limit of quantification (LOQ) of the HPLC for the water samples were 20 and $50 \mathrm{ng} / \mathrm{l}$, respectively.

\section{Zooplankton}

Zooplankton was sampled from each microcosm on $-7,-1$, $6,13,20,27$, and 41 days postapplication using a Perspex tube (length, $66 \mathrm{~cm}$; diameter, $3.9 \mathrm{~cm}$ ). Subsamples were collected from several spots in the microcosms to obtain a 1.5-1 sample, of which 11 was filtered through a plankton net (mesh size, $55 \mu \mathrm{m}$; Hydrobios, Kiel, Germany). The filtered water was poured back into the corresponding microcosm and the collected zooplankton was preserved with formalin (final volume, 4\%). Zooplankton was identified under an inverted microscope and binocular microscope. Rotifers and cladocerans were identified to the lowest practical taxonomic level. Copepods were identified to suborder, and a distinction was made between nauplii and more mature stages. Ostracods were not identified any further.

\section{Macroinvertebrates}

At the start of the experiment, the macroinvertebrates A. aquaticus (10 specimens, adults) and G. pulex (10 specimens, adults) were introduced into the microcosms. The macroinvertebrates (A. aquaticus and G. pulex) were sampled by means of the litter bag technique (Brock et al. 1982). A litter bag consists of a Petri dish (diameter: $11.6 \mathrm{~cm}$ ) filled with $2 \mathrm{~g}$ of dried Populus sp. leaves and covered with a stainless-steel gauze (mesh-size: $0.7 \times 0.7 \mathrm{~mm}$ ) with two entry holes (diameter: $0.5 \mathrm{~cm}$ ) punctured in it. Each microcosm contained two litter bags, from which in one of the litter bags the entry holes were closed with stoppers to avoid the passage of invertebrates. On days 6, 22, and 47 postapplication the litter bags were lifted and emptied in a white container. The numbers of A. aquaticus and G. pulex present in both litter bags were counted and afterward returned to their originating microcosm. At the end of the experiment all A. aquaticus and G. pulex present in the microcosms were counted.

\section{Chlorophyll $a$}

The chlorophyll $a$ content of the phytoplankton was sampled simultaneously with zooplankton. Of the remaining 0.51 of the original $1.5-1$ sample a quantified sample $(0.2 \mathrm{l})$ was used for chlorophyll $a$ analysis. The water sample was filtered through a glass-fiber filter (e.g., GF/C; diameter, $4.7 \mathrm{~cm}$; mesh size, $1.2 \mu \mathrm{m}$ ) using a vacuum pump. The filtrate and the remaining unfiltered sample were returned into the corresponding microcosms. The filter was then wrapped in aluminum foil and stored deep frozen at a temperature below $-20^{\circ} \mathrm{C}$ for a maximum period of 8 weeks. After ethanol extraction of the pigments, measurements of chlorophyll $a$ content was carried out using a Shimadzu 1601 PC UV-visible spectrophotometer, following the method described by Moed and Hallegraeff (1978).

\section{Decomposition of Populus Leaves}

Decomposition of particulate organic matter (POM) was studied by means of the litter bag technique (Brock et al. 1982) using Populus sp. leaves. Before use, the leaves were soaked three times for 2 days in water to remove the soluble humic compounds and then dried in an oven for 
3 days at $60^{\circ} \mathrm{C}$. At the end of each 2-week incubation period (days 6 and 22 postapplication), the litter bag was gently washed in the overlying water of the microcosm and emptied in a white tray to separate POM from invertebrates and sediment particles using tap water. The POM was dried in aluminum foil at $105^{\circ} \mathrm{C}$ for a minimum of $24 \mathrm{~h}$ to determine dry weight.

\section{Community Metabolism}

Dissolved oxygen (DO), $\mathrm{pH}$, and temperature were measured at $10 \mathrm{~cm}$ depth in the microcosms. The measurements were performed at a fixed time 2 days before application and two or three times per week after application of the test substance. DO was measured using a WTWOxi196 oxygen meter and WTW EOT196 oxygen probe. $\mathrm{pH}$ and temperature were measured using a WTWpH 323 meter.

\section{Statistics}

Prior to statistical analysis, zooplankton and macroinvertebrate data were $\ln (2 x+1)$-transformed, where $x$ is the abundance in number per 1 . This was done to down-weigh high abundance values and to approximate a normal distribution for the data (Van den Brink et al. 1995).

The no observed effect concentration (NOEC) calculations at taxon or parameter level $(p \leq 0.05)$ were carried out using the Williams test (ANOVA; Williams 1972). The test assumes that the mean response of the variable is a monotonic function of the treatment, thus expecting increasing effects with increasing dose. The analyses were performed with the Community Analysis computer program (Hommen et al. 1994), resulting in an overview of NOECs on each sampling day for the data analyzed.

The effects of the treatment with ivermectin on the zooplankton community was analyzed by the principal response curves (PRC) method (Van den Brink and Ter Braak 1998, 1999). The statistical significance of treatment effects at the community level were also tested using Monte Carlo permutation tests. The significance of the PRC diagram was tested by Monte Carlo permutation of species counts (i.e., by permuting entire time series in the partial redundancy analysis from which PRC is derived). Monte Carlo permutation tests were also performed per sampling date, allowing the significance of the effects of a treatment regime to be tested for each sampling date.

In addition to the overall significance of the effects of a treatment regime on a community, each treatment was also compared to the controls to determine the significance of any treatment-related effects so as to identify the NOEC at the community level. The NOEC calculations were carried out by applying the Williams test to the sample scores of the first principal component of each sampling date in turn [for rationale, see Van den Brink et al. (1996)]. Data were evaluated for artifacts relating to small magnitude of measured counts or having no treatment-related concentration-response and/or no clear causality with community interactions or timing (European Commission HCPD-G 2002). Effects (based on univariate tests) were considered consistent when they showed statistically significant increases or decreases for at least two consecutive sampling points and were then further evaluated in relation to possible artifacts.

\section{Results}

Fate of Ivermectin

Ivermectin concentrations decreased rapidly during the experimental period (Fig. 1). Concentrations decreased on average by $42 \pm 21 \%$ (mean $\pm \mathrm{SD}$ ) in $3 \mathrm{~h}$ and remained more or less constant for 2 days. During the analysis of samples from the first week after application, a leakage in a drain of the HPLC apparatus was observed. This resulted in an unequal intake of the water sample. Because the same samples were used for the second analysis, some samples had less volume left for a second injection. From both analyses, the highest concentration was used for each sample, but still this could be an underestimation of the actual concentration in the microcosms during the first week after application. In calculating the dissipation time $50 \%\left(\mathrm{DT}_{50}\right)$ for the posttreatment period, an exponential decrease was assumed. Ivermectin showed $\mathrm{DT}_{50}$ values ranging from 1.1 to 8.3 days. All data above the detection limit were used. The lowest test concentration was not used because this concentration was within the range of the detection limit. From the analyses of the first week, the highest concentration was used to calculate the $\mathrm{DT}_{50}$ values.

\section{Zooplankton}

In total, 33 zooplankton taxa were identified in the microcosms during the experiment. Rotifers dominated in the microcosms, followed by copepods and cladocerans.

The PRC analysis indicated that $47 \%$ of all variance could be attributed to the treatment regime (Fig. 2). Multivariate analysis of the zooplankton community showed consistent clear treatment effects at the 1000-ng/l treatment level on consecutive samplings. At this level, reductions were significant from day 20 until day 27 . At the 10,000$\mathrm{ng} / \mathrm{l}$ treatment level, reductions were significant on all postapplication sampling days, thus from day 6 until day 41 


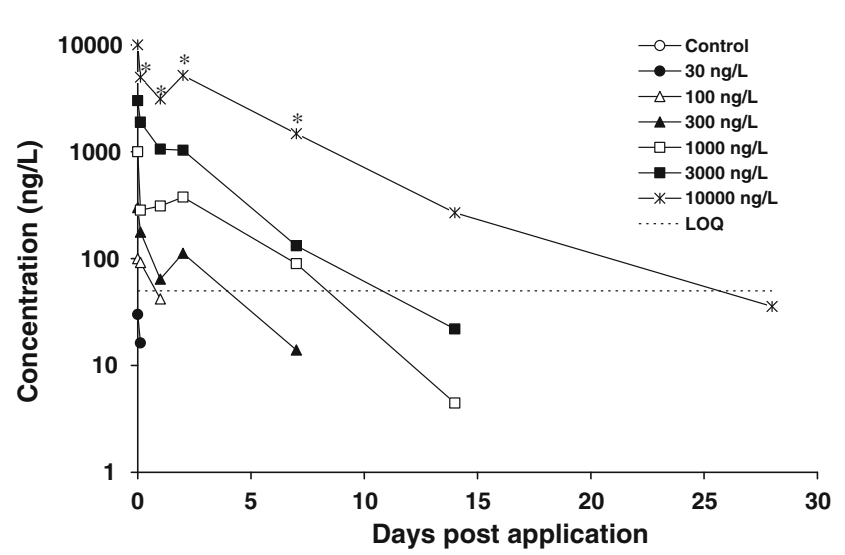

Fig. 1 Dynamics of ivermectin concentrations in the different treatments. Average concentrations of two replicates are shown. The asterisk denotes that the concentration measured during the first week could be an underestimation of the actual concentrations in the microcosms

(Table 1). The lowest NOEC community $_{\text {was found on day } 27}$ at the 100-ng/l treatment level (Table 1). The community response of zooplankton was characterized by an increase of Rotifera and a decrease of Cladocera. The Copepoda decreased the first 2 weeks after application and showed increasing numbers from day 27 postapplication. Especially, Cladocera species (Chydorus sphaericus, Daphnia longispina) showed high positive weights in the PRC diagram (Fig. 2). All Rotifera taxa show negative weights (Fig. 2).

Statistical significant deviations (Williams test, $p \leq 0.05$ ) on two consecutive sampling days were encountered for 14 out of the 33 taxa on population level (Table 1). A $\mathrm{NOEC}_{\text {population }}$ of $30 \mathrm{ng} / \mathrm{l}$ was found for Ceriodaphnia $\mathrm{sp}$. on two consecutive sampling days (i.e., day 6 and 13 postapplication) during the application period (Fig. 3; Table 1). Ceriodaphnia sp. were the most sensitive organisms observed in this experiment. For one of the identified taxa, an isolated NOEC of less than the 30-ng/l treatment level could be calculated. This taxon (Alona sp.), however, was found in low numbers. Consistent statistically significant reductions in $C$. sphaericus and $D$. longispina only occurred at, respectively, 300 and $1000 \mathrm{ng} / \mathrm{l}$ (Fig. 3; Table 1). The copepod taxa (nauplii, Cyclopoida) showed consistent significant reductions on days 6 and 13 post application at the 10,000-ng/l treatment level (Fig. 3; Table 1). In the case of nauplii, significant increases on two consecutive sampling days were indicated for the 10,000$\mathrm{ng} / \mathrm{l}$ treatment level at the end of the experiment. For Cyclopoida, a single NOEC of $3000 \mathrm{ng} / \mathrm{l}$ was calculated for day 27 based on an increase in abundance. Nine rotifer taxa (Fig. 4a, b; Table 1) showed a consistent statistical significant increase in abundance at the 10,000-ng/l treatment

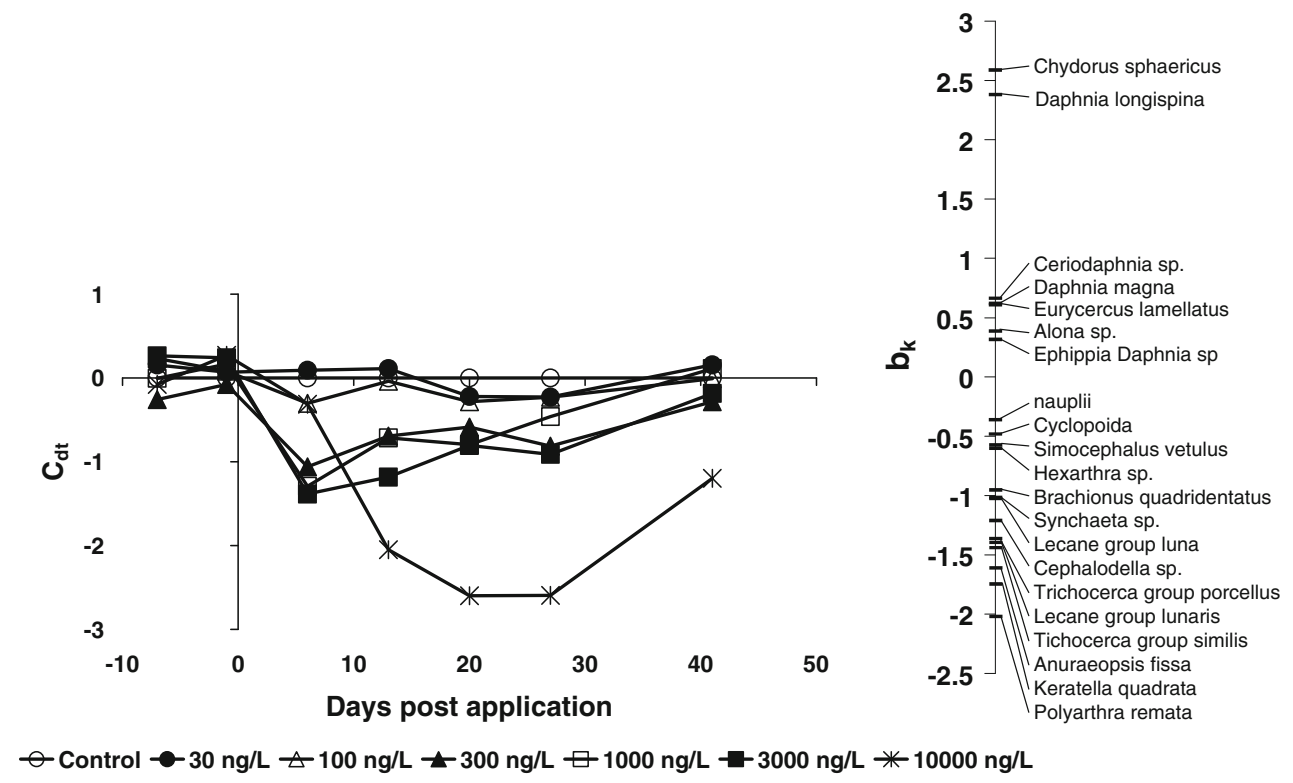

Fig. 2 PRCs resulting from the analysis of the zooplankton dataset, indicating the effects of ivermectin on the zooplankton community. Twenty-three percent of all variance could be attributed to the sampling date; this is displayed on the horizontal axis. Forty-seven percent of all variance could be attributed to treatment level, of which $39 \%$ is displayed on the vertical axis. The lines represent the development of the treatments in time. The species weight $\left(b_{k}\right)$ can be interpreted as the affinity of the taxon with the PRCs $\left(\mathrm{c}_{\mathrm{dt}}\right)$. Taxa with a species weight between 0.25 and -0.25 are not shown. A Monte Carlo permutation test indicated that the diagram displays a significant amount of the variance explained by treatment $(p=0.002)$. The significance of the differences indicated in the figure is given in Table 1 
Table 1 Results of Monte Carlo permutation tests ( $p$ values) and the NOEC calculations as performed using the Williams test

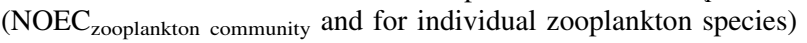

\begin{tabular}{|c|c|c|c|c|c|c|c|}
\hline Day & -7 & -1 & 6 & 13 & 20 & 27 & 41 \\
\hline Community ( $p$ value) & 0.376 & 0.721 & 0.001 & 0.001 & 0.001 & 0.001 & 0.006 \\
\hline $\mathrm{NOEC}_{\text {community }}$ & & & 3000 & 1000 & 300 & 100 & 3000 \\
\hline Ceriodaphnia sp. & & & $30(-)$ & $30(-)$ & & & \\
\hline Chydorus sphaericus & & & $30(-)$ & $100(-)$ & $100(-)$ & $100(-)$ & $100(-)$ \\
\hline Daphnia longispina & & & $300(-)$ & $300(-)$ & $1000(-)$ & $1000(-)$ & $1000(-)$ \\
\hline Cyclopoida & & & $1000(-)$ & $3000(-)$ & & $3000(+)$ & \\
\hline Nauplii & & & $3000(-)$ & $3000(-)$ & & $1000(+)$ & $3000(+)$ \\
\hline Cephalodella sp. & & & & $3000(+)$ & $1000(+)$ & $3000(+)$ & $3000(+)$ \\
\hline Anuraeopsis fissa & & & $3000(-)$ & $3000(+)$ & $3000(+)$ & $3000(+)$ & \\
\hline Lecane group lunaris & & & & $3000(+)$ & $3000(+)$ & $3000(+)$ & $3000(+)$ \\
\hline Polyarthra remata & & & & $3000(+)$ & $3000(+)$ & $3000(+)$ & \\
\hline Lecane group luna & & & & & $3000(+)$ & $3000(+)$ & $3000(+)$ \\
\hline Brachionus quadridentatus & & & & & $3000(+)$ & $3000(+)$ & $3000(+)$ \\
\hline Trichocerca group porcellus & & & & $3000(+)$ & $3000(+)$ & $3000(+)$ & \\
\hline Keratella quadrata & & & & & $3000(+)$ & $3000(+)$ & \\
\hline Synchaeta sp. & & & & $3000(+)$ & $3000(+)$ & & \\
\hline Total species richness & & & $3000(-)$ & & $3000(+)$ & $3000(+)$ & \\
\hline Cladocera species richness & & & $100(-)$ & $100(-)$ & $100(-)$ & $100(-)$ & \\
\hline Rotifera species richness & & & & $3000(+)$ & $3000(+)$ & $3000(+)$ & \\
\hline
\end{tabular}

Note: Empty cells denote a NOEC of $>10,000 \mathrm{ng} / \mathrm{l}$

level during the postapplication period. Based on decreased total zooplankton species richness, a single NOEC of $3000 \mathrm{ng} / \mathrm{l}$ at day 6 directly after application was found and two consecutive NOECs of $3000 \mathrm{ng} / \mathrm{l}$ based on an increase in total zooplankton species richness were calculated for days 20 and 27 (Fig. 5; Table 1). When focusing on species richness of Cladocera only, consistent statistically significant reductions were found at the 300-ng/l treatment level (from day 6 to day 27; Table 1). In contrast to Cladocera species richness, the Rotifera showed a statistically significant increase in species richness from day 13 to day 27 (Table 1). During the experiment, clear responses could be observed in total abundance due to shifts in species dominance (from large cladocerans to small rotifers) at the highest treatment level.

\section{Macroinvertebrates}

A consistent statistically significant reduction in numbers (Williams test, $p \leq 0.05$ ) was observed at the $1000-\mathrm{ng} / 1$ treatment level for $G$. pulex. One isolated NOEC of $300 \mathrm{ng} / 1$ was calculated for A. aquaticus 22 days posttreatment (Fig. 6; Table 2). At the end of the experiment, no effects were observed in the numbers of A. aquaticus and G. pulex.
Chlorophyll $a$

The chlorophyll $a$ content (see Fig. 7; Table 2) of the phytoplankton showed consistent concentration-related effects on two consecutive sampling days (day 6 and day 13 postapplication) at the $300-\mathrm{ng} / \mathrm{l}$ treatment level and higher (Williams test, $p \leq 0.05$ ).

\section{Decomposition of Populus Leaves}

No consistent treatment-related response was observed. Only once (day 22), a NOEC at the 300-ng/l treatment level and higher could be calculated based on an increase in remaining dry weight (Williams test, $p \leq 0.05$; Table 2).

\section{Community Metabolism}

The water quality variables $\mathrm{DO}$ and $\mathrm{pH}$ indicated a consistent increased primary production in the highest treatment level from day 15 until day 44 posttreatment (Fig. 8; Table 2). Compared to the controls, DO and $\mathrm{pH}$ were elevated at this treatment level. At day 5 posttreatment, an isolated NOEC of $3000 \mathrm{ng} / \mathrm{l}$ was calculated for both DO as $\mathrm{pH}$. Consistent NOECs were found for $\mathrm{pH}$ at the 300-ng/l treatment level at day 27 and day 29 posttreatment (Williams test, $p \leq 0.05$ ). 

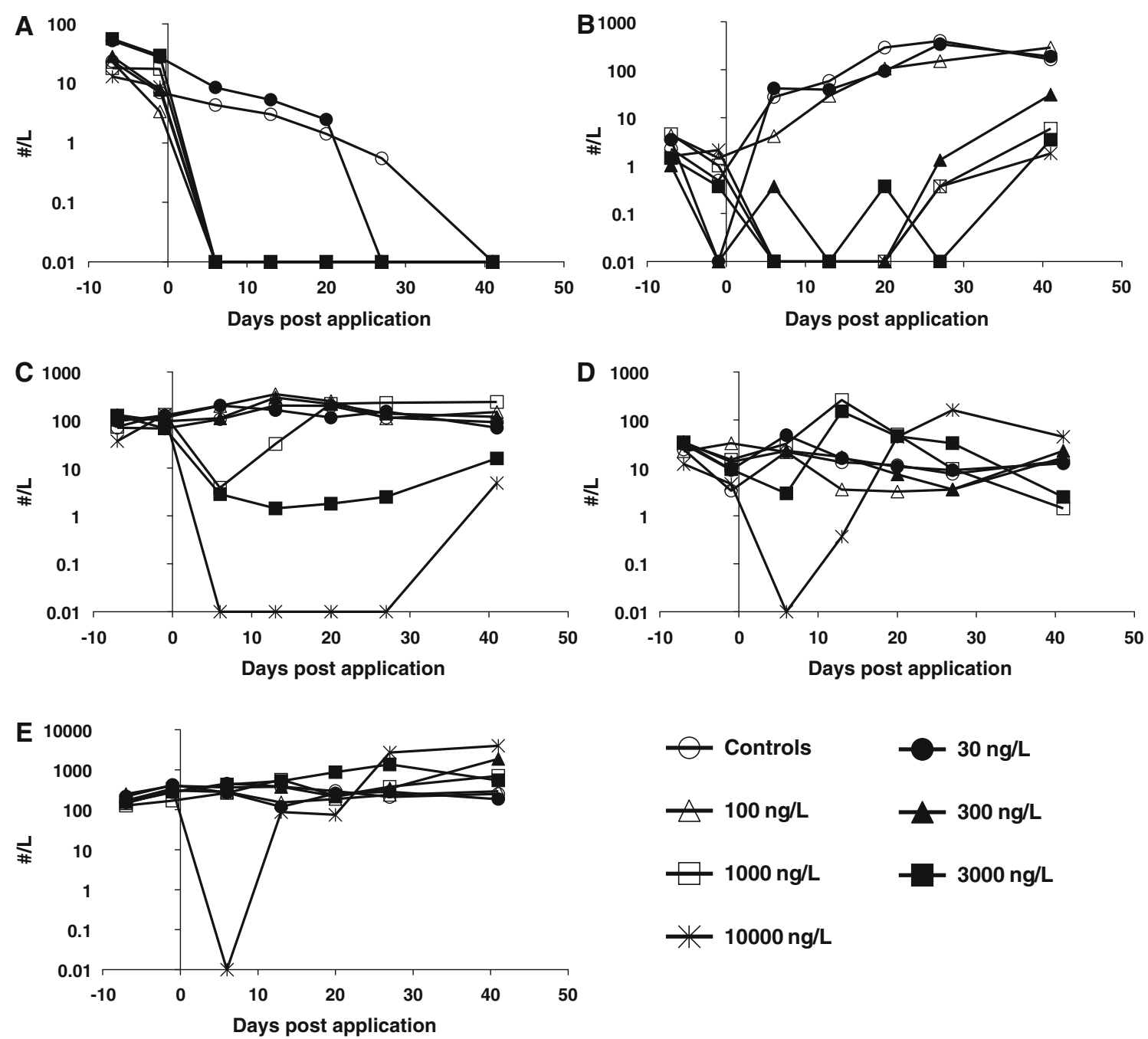

Fig. 3 Changes in numbers of the zooplankton taxa for which consistent negative treatment effects were calculated, expressed as the geometric means of the numbers per liter counted, for each treatment

level of Ceriodaphnia sp. (a), Chydorus sphaericus (b), Daphnia longispina (c), Cyclopoida (d), and nauplii (e). See Table 1 for significance of indicated differences

\section{Discussion}

Fate

Due to the leakage in a drain of the HPLC apparatus during the measurements of samples from the first week, actual concentrations might have been underestimated, although patterns in the data could still be distilled.

As expected, ivermectin showed a rapid dissipation rate from the water column in the microcosms $\left(\mathrm{DT}_{50}\right.$ ranging from 1.1 to 8.3 days). Because ivermectin is a lipophilic compound $\left[K_{\mathrm{ow}}=1651\right.$ (Bloom and Matheson 1993) and $K_{\mathrm{oc}}=12,600-15,700$ (Halley et al. 1989)], it tends to bind strongly to organic materials and sediments. Additionally, ivermectin is rapidly photodegraded in surface water [degradation half-life in summer $=0.5$ days or less; Halley et al. (1993)]. In laboratory water/sediment systems,

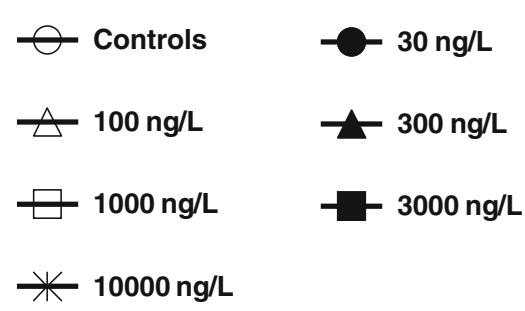

ivermectin has been shown to have a $\mathrm{DT}_{50}$ of $2.9 \pm 0.4$ days in the water compartment (Loffler et al. 2005). In outdoor aquatic mesocosms, its $\mathrm{DT}_{50}$ in water was found to be 3-5 days, after a 4-day treatment (Sanderson et al. 2007). The rapid dissipation rate of ivermectin in this study is comparable to the other studies. For example, the same dissipation pattern of the test substance concentrations was found in an acute Daphnia toxicity test with abamectin, where concentrations of abamectin decreased by about $40 \%$ in a few hours and then remained constant for $48 \mathrm{~h}$ (Tisler and Kozuh Erzen 2006).

\section{Direct Effects}

Clear effects on the zooplankton community were already found at the 300-ng/l treatment level (Fig. 2; Table 1) and at the 100-ng/l treatment level for populations 

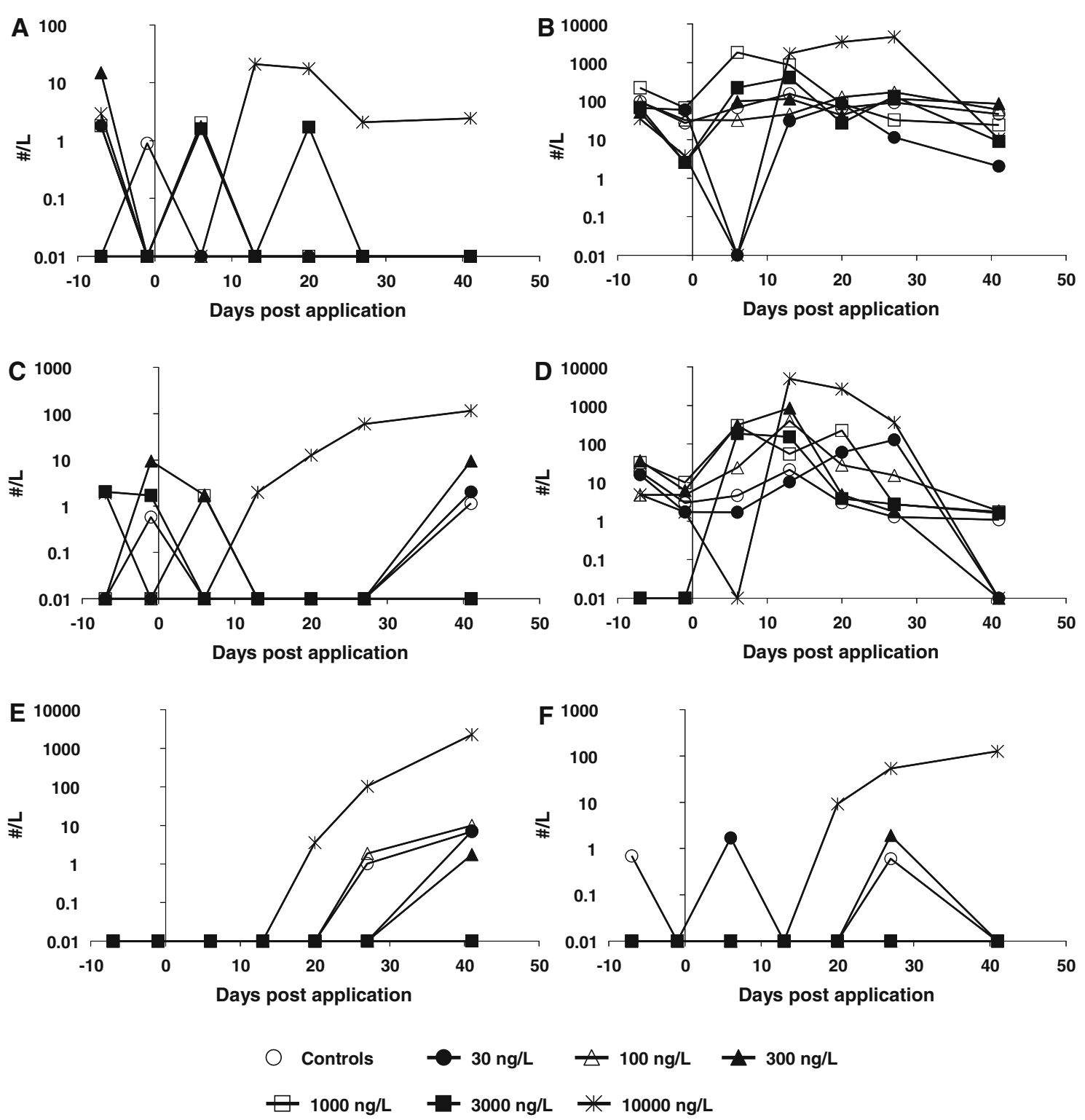

Fig. 4 A Changes in numbers of the zooplankton taxa for which consistent positive treatment effects were calculated, expressed as the geometric means of the numbers per liter counted, for each treatment level of Cephalodella sp. (a), Anuraeopsis fissa (b), Lecane group lunaris (c), Polyarthra remata (d), Lecane group luna (e), and Brachionus quadridentatus (f). See Table 1 for significance of

(Ceriodaphnia sp.; Fig. 3; Table 1). These lowest observed effect concentrations (LOECs) are higher then those reported by Sanderson et al. (2007), who found effects at the 30-ng/l treatment for species richness of cladocera and copepods and abundance of cladocera. This difference in response is probably explained by the fact that in our microcosm study, ivermectin was applied once, whereas in the outdoor mesocosm test, the treatment occurred over 4 days. During these 4 days the nominal concentration was kept as constant as possible (Sanderson et al. 2007). indicated differences. B Changes in numbers of the zooplankton taxa for which consistent positive treatment effects were calculated, expressed as the geometric means of the numbers per liter counted, for each treatment level of Trichocerca group porcellus (g), Keratella quadrata (h), and Synchaeta sp. (i). See Table 1 for significance of indicated differences

In acute toxicity studies performed with $D$. magna in the laboratory, $48-\mathrm{h} \mathrm{LC}_{50}$ values as low as $5.7 \mathrm{ng} / \mathrm{l}$ were found (Garric et al. 2007). The chronic toxicity of ivermectin assessed in a laboratory study was extremely high to D. magna with a LOEC at the 0.001-ng/l treatment level, based on growth and reproduction. This concentration was far below the analytical limit of detection (Garric et al. 2007). In acute (based on mobility) and chronic (reproduction) exposure tests with the closely related abamectin, a $48-\mathrm{h} \mathrm{EC}_{50}$ of $250 \mathrm{ng} / \mathrm{l}$ and a NOEC of $4.7 \mathrm{ng} / \mathrm{l}$ were 

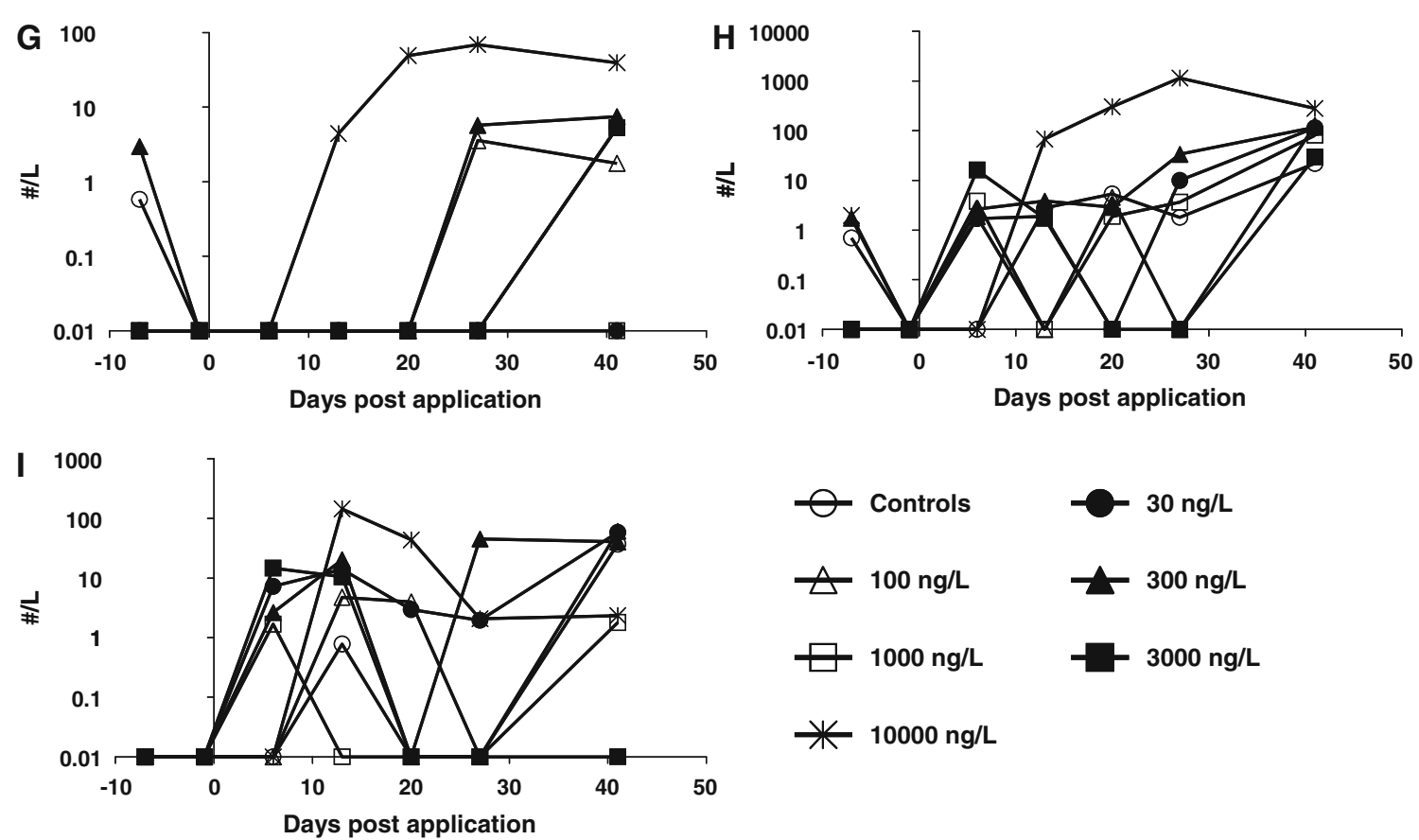

Fig. 4 continued

obtained (Tisler and Kozuh Erzen 2006); the 48-h $\mathrm{EC}_{50} /$ $\mathrm{LC}_{50}$ of doramectin was $100 \mathrm{ng} / \mathrm{l}$ and that of eprinomectin was $450 \mathrm{ng} / \mathrm{l}$ (Boxall et al. 2004; Taylor 1999). Comparing the results from laboratory studies with this microcosm study indicates that cladocerans are the most sensitive species tested (Boxall et al. 2004; Garric et al. 2007). Differences in sensitivity of cladocerans to ivermectin in the laboratory studies and the cosm studies can be explained by a number of factors. A possible explanation might be that in laboratory studies, the concentration is kept as constant as possible, whereas in our microcosms study, ivermectin was allowed to dissipate rapidly. In addition, organic material or sediment was not used in other laboratory studies, and, as Halley et al. (1989) showed, the acute toxicity of ivermectin to Daphnia can be diminished by a factor of about 100 in the presence of sediment. Another possible explanation is that other acute tests were carried out in complete darkness, whereas ivermectin tends to dissipate rapidly under influence of light (Halley et al. 1993). A fourth explanation is that sensitive sublethal end points (e.g., growth) studied in chronic laboratory studies (Garric et al. 2007) cannot be studied easily in cosm studies, where the consequences for the fitness of a population most probably will become manifest only after 40 days.

Significant effects on macroinvertebrates (G. pulex and A. aquaticus) were found at the 1000-ng/l treatment level and higher. This effect on the macroinvertebrates could be an overestimation of mortality because it is possible that individuals were inactive for a period and subsequently were not caught with the artificial substrates. In a laboratory test performed with a mixture of $G$. duebeni and G. zaddachi, a 96-h $\mathrm{LC}_{50}$ of $33 \mathrm{ng} / \mathrm{l}$ was found (Grant and Briggs 1998). Similarly, Neomysis integer (crustacean) was very sensitive in acute tests, with values ranging from $48-\mathrm{h} \mathrm{LC}_{50}=26 \mathrm{ng} / \mathrm{l}$ to $96-\mathrm{h} \mathrm{LC}_{50}=70 \mathrm{ng} / \mathrm{l}$ (Davies et al. 1997; Grant and Briggs 1998). In an outdoor mesocosm study, consistent effects on invertebrates (Ephemeroptera) were found at the 1000-ng/l treatment level, which is comparable to our study. After 265 days, because the Ephemeropterans had still not recovered fully compared to the controls, it was assumed that Ephemeroptera are more active in the sediment compared to other species and thus have a relatively high exposure via the sediment (Sanderson et al. 2007). At the end of the present study, no treatment-related effects were evident for the populations of G. pulex and A. aquaticus. Toxic effects of ivermectin on the freshwater snail Biomphalaria glabrata have been reported at concentrations much higher than those in this study: its $24-\mathrm{h} \mathrm{CC}_{50}$ was determined to be 30,000 ng/l (Matha and Weiser 1988), explaining the absence of effects on $L$. stagnalis.

\section{Indirect Effects}

The elevated levels of $\mathrm{pH}$ and DO at the 1000-ng/l treatment level and higher, indicating increased primary production, was supported by the increased chlorophyll $a$ content at the 1000-ng/l treatment and higher treatments. The same phenomenon was found in outdoor mesocosms, where DO and pH also increased at the 1000-ng/l treatment 


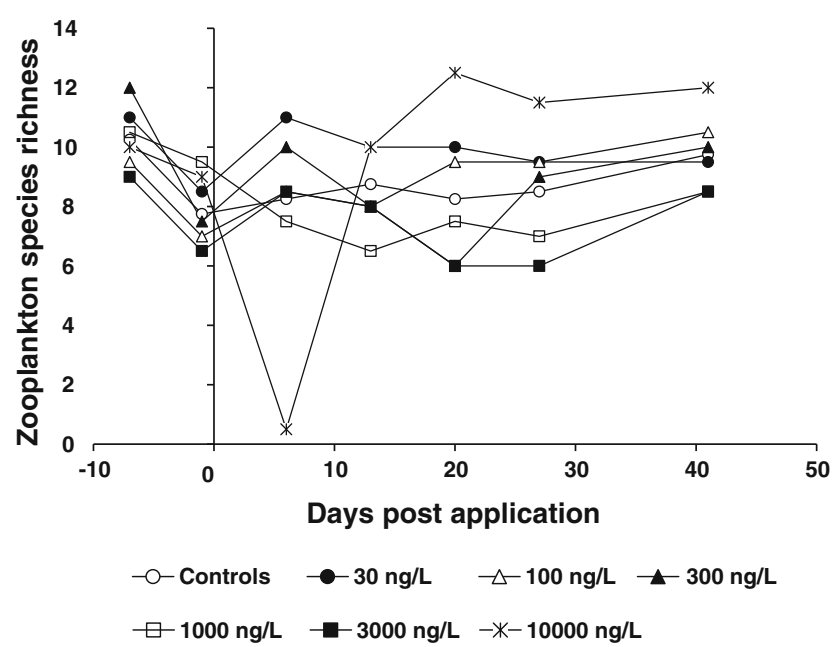

Fig. 5 Dynamics in the total zooplankton species richness in the different treatments. The richness numbers are the geometric means per treatment level
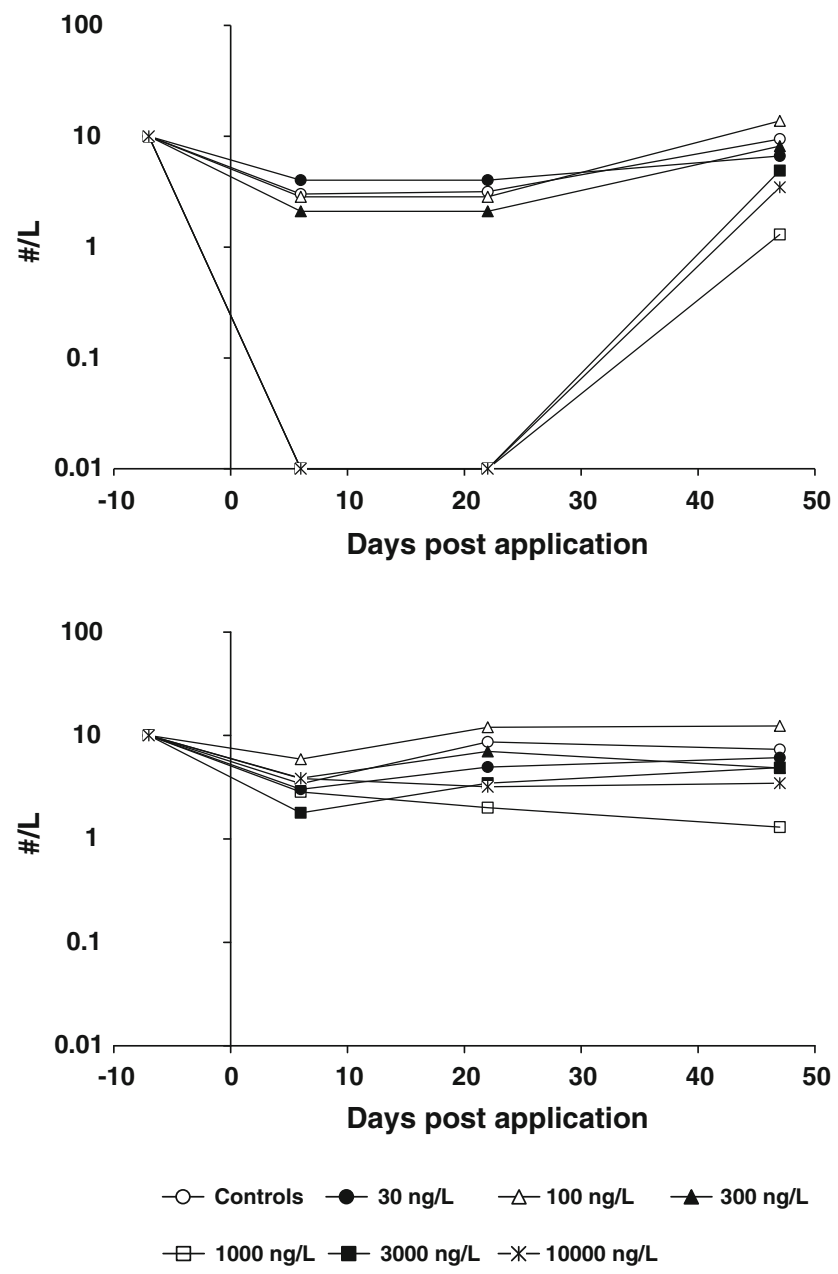

Fig. 6 Changes in abundance of Gammarus pulex (a) and Asellus aquaticus (b). Abundance values (numbers per liter) are the geometric means of the numbers counted per treatment level level, although in the same study no effects could be demonstrated on chlorophyll $a$ content (Sanderson et al. 2007). At the end of the microcosm experiment, the presence of a floating blue-green algae community was observed in microcosms with the highest treatment level. However, this floating algae community was not sampled for the chlorophyll $a$ measurements. Because ivermectin directly affects cladocerans and macroinvertebrates (Boxall et al. 2004; Sanderson et al. 2007), rotifers and phytoplankton could increase due to a decreased grazing pressure of Cladocora. This relationship was also often found in cosm studies with pesticides (e.g., Van Wijngaarden et al. 2006). Due to selective toxicity of ivermectin, an increase of rotifers at the highest treatment level resulted in a (shortterm) increase of biodiversity (Fig. 5; Table 1). The results support the hypothesis that intermediate disturbance increases species richness/diversity (Connell 1978). In experiments with the insecticide carbaryl, this same phenomenon was found (Hanazato 1998).

\section{Risk Assessment}

The highest measured concentration of ivermectin in surface water reported in the open literature known to us is $4.4 \mathrm{ng} / \mathrm{l}$ (Nessel et al. 1989). Predicted environmental concentration (PEC) calculations using exposure models suggest that in surface water, concentrations of 25 up to $60 \mathrm{ng} / \mathrm{l}$ can be reached (Montforts et al. 2004; Sanderson et al. 2007). Based on our study, an overall NOEC of $30 \mathrm{ng} / \mathrm{l}$ is suggested. This implies that there could be a potential environmental risk after a single accidental spill of ivermectin into surface waters.

\section{Cosm Evaluation}

The present indoor microcosm study was designed to determine the effects of ivermectin on a plankton-dominated system with additional macroinvertebrate species. Taken together, the findings in this indoor microcosm study suggest that, in general, the same results can be obtained as with large outdoor mesocosms (Sanderson et al. 2007). Because there are differences in design between the studies, the NOECs were not always the same. Main differences between these studies are the duration of application and the total length of the studies; therefore, comparisons should be made with some prudence. Comparable results were obtained in experiments with pesticides where the use of indoor microcosms gave the same general threshold values as in larger-scale studies (Daam and Van den Brink 2007).

Thus, for calculating threshold values, the simple design of the indoor microcosms offers the possibility to perform experiments with a relatively high ecological realism and is much more inexpensive than larger-scale 


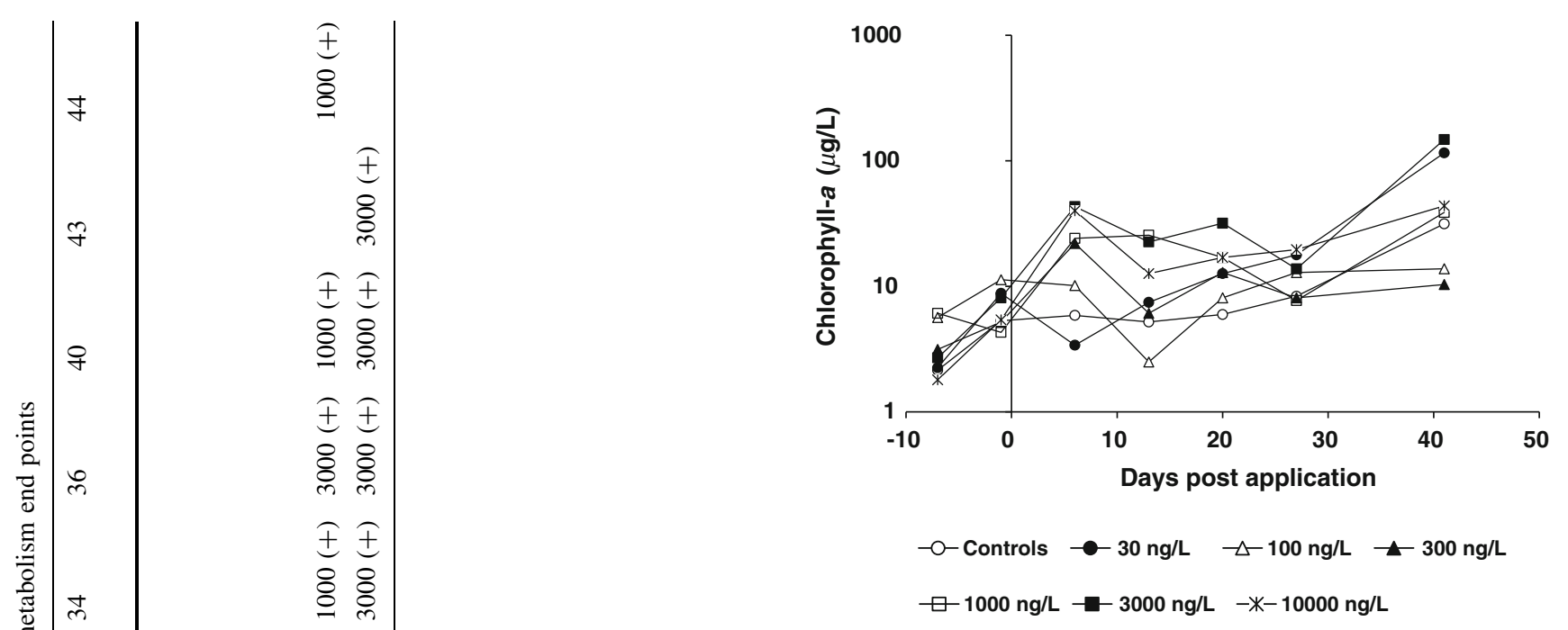

Fig. 7 Dynamics of chlorophyll $a$ concentrations in the different treatments

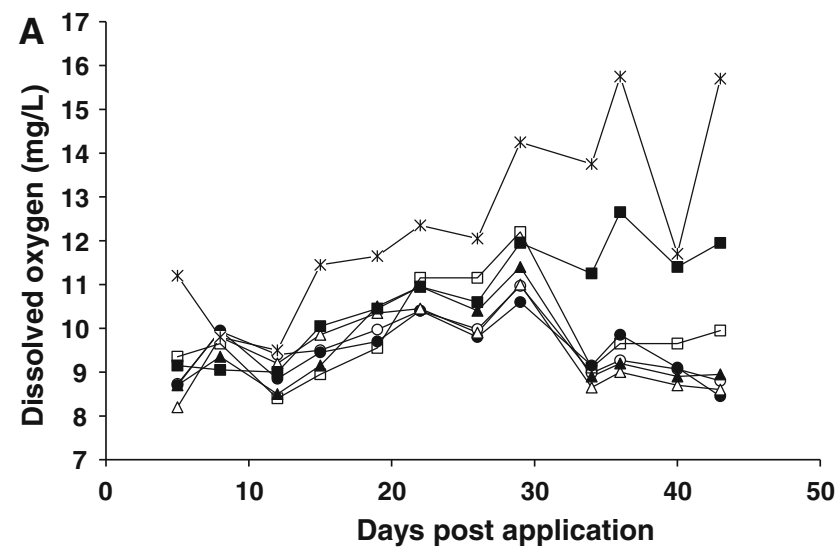

B 11

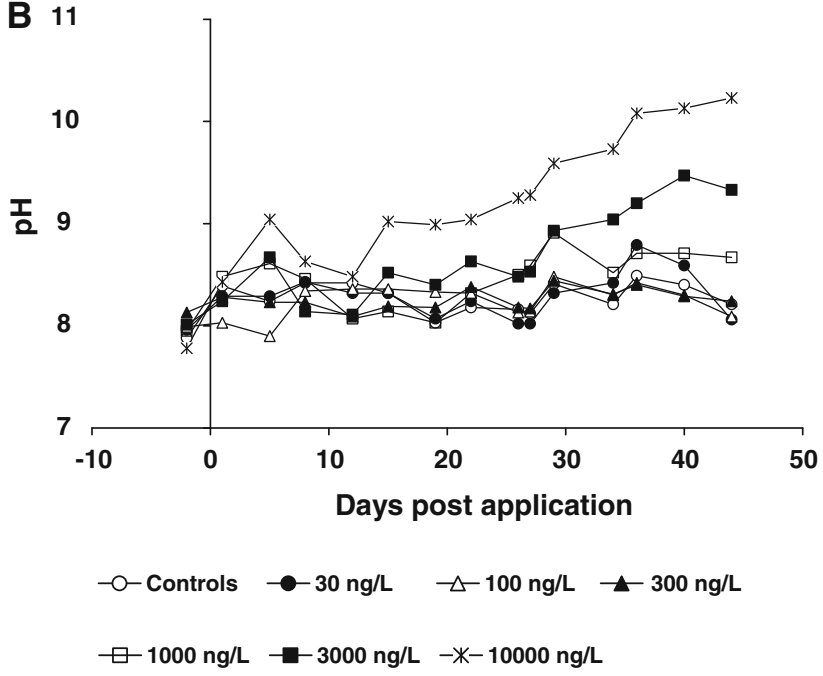

Fig. 8 Dynamics of dissolved oxygen (a) and $\mathrm{pH}(\mathbf{b})$ in the different treatments 
model ecosystems. Summarizing, the indoor microcosm study is a useful tool in the risk assessment of veterinary pharmaceuticals.

Acknowledgments The authors are indebted to Rene Aalderink, Steven Crum, Caroline van Rhenen, and Hans Zweers for practical assistance and useful discussions. We thank Theo Brock and Linda McPhee for reviewing the manuscript.

Open Access This article is distributed under the terms of the Creative Commons Attribution Noncommercial License which permits any noncommercial use, distribution, and reproduction in any medium, provided the original author(s) and source are credited.

\section{References}

Adelsberger H, Scheuer T, Dudel J (1997) A patch clamp study of a glutamatergic chloride channel on pharyngeal muscle of the nematode Ascaris suum. Neurosci Lett 230:183-186

Bloom RA, Matheson JC (1993) Environmental assessment of avermectins by the United States Food and Drug Administration. Vet Parasitol 48:281-294

Boxall AB, Fogg LA, Blackwell PA, Kay P, Pemberton EJ, Croxford A (2004) Veterinary medicines in the environment. Rev Environ Contam Toxicol 180:1-91

Brock TCM, Huijbrechts CAM, Van de Steeg-Huberts MJHA, Vlassak MA (1982) In situ studies on the breakdown of Nymphoides peltata (Gmel.) O. kuntze (Menyanthacea); some methodological aspects of the litter bag technique. Hydrobiol Bull 16:35-49

Campbell WC, Fisher MH, Stapley EO, Albers-Schonberg G, Jacob TA (1983) Ivermectin: a potent new antiparasitic agent. Science 221:823-828

Campbell PJ, Arnold DJS, Brock TCM, Grandy NJ, Heger W, Heimbach F, Maund SJ, Streloke M (1999) Guidance document on higher-tier aquatic risk assessment for pesticides (HARAP). SETAC-Europe, Brussels

Connell JH (1978) Diversity in tropical rain forests and coral reefs. Science 199:1302-1310

Daam MA, Van den Brink PJ (2007) Effects of chlorpyrifos, carbendazim, and linuron on the ecology of a small indoor aquatic microcosm. Arch Environ Contam Toxicol 53:22-35

Davies IM, McHenery JG, Rae GH (1997) Environmental risk from dissolved ivermectin to marine organisms. Aquaculture 158:263-275

Edwards CA, Atiyeh RM, Rombke J (2001) Environmental impact of avermectins. Rev Environ Contam Toxicol 171:111-137

European Commission HCPD-G (2002) Guidance document on aquatic ecotoxicology in the context of the Directive 91/414/ EEC. Working Document SANCO/3268/2001 rev.4 (final). European Commission, Brussels, Belgium

Fent K, Weston AA, Caminada D (2006) Ecotoxicology of human pharmaceuticals. Aquat Toxicol 76:122-159

Garric J, Vollat B, Duis K, Pery A, Junker T, Ramil M, Fink G, Ternes TA (2007) Effects of the parasiticide ivermectin on the cladoceran Daphnia magna and the green alga Pseudokirchneriella subcapitata. Chemosphere 69:903-910

Grant A, Briggs AD (1998) Toxicity of ivermectin to estuarine and marine invertebrates. Marine Pollut Bull 36:540-541

Halley BA, Jacob TA, Lu AYH (1989) The environmental impact of the use of ivermectin: environmental effects and fate. Chemosphere 18:1543-1563
Halley BA, Van den Heuvel WJ, Wislocki PG (1993) Environmental effects of the usage of avermectins in livestock. Vet Parasitol 48:109-125

Halling-Sørensen B, Nielsen SN, Lanzky PF, Ingerslev F, Lutzhoft $\mathrm{HCH}$, Jorgensen SE (1998) Occurrence, fate and effects of pharmaceutical substances in the environment: a review. Chemosphere 36:357-394

Hanazato $\mathrm{T}$ (1998) Response of a zooplankton community to insecticide application in experimental ponds: a review and the implications of the effects of chemicals on the structure and functioning of freshwater communities. Environ Pollut 101:361373

Hommen U, Düllmer U, Veith D (1994) A computer program to evaluate plankton data from freshwater field tests. In: Hill LA, Heimbach F, Leeuwangh P, Matthiesen P (eds) Freshwater field tests for hazard assessment of chemicals. Lewis Publishers, Boca Raton, FL, pp 503-513

Kitzman D, Wei SY, Fleckenstein L (2006) Liquid chromatographic assay of ivermectin in human plasma for application to clinical pharmacokinetic studies. J Pharm Biomed Anal 40:1013-1020

Kolpin DW, Furlong ET, Meyer MT, Thurman EM, Zaugg SD, Barber LB, Buxton HT (2002) Pharmaceuticals, hormones, and other organic wastewater contaminants in US streams, 19992000: a national reconnaissance. Environ Sci Technol 36:12021211

Kools SA, Moltmann JF, Knacker T (2008) Estimating the use of veterinary medicines in the European union. Regul Toxicol Pharmacol 50:59-65

Leeuwangh P, Brock TCM, Kersting K (1994) An evaluation of 4 types of fresh-water model ecosystem for assessing the hazard of pesticides. Hum Exp Toxicol 13:888-899

Loffler D, Rombke J, Meller M, Ternes TA (2005) Environmental fate of pharmaceuticals in water/sediment systems. Environ Sci Technol 39:5209-5218

Lopes C, Charles S, Vollat B, Garric J (2009) Toxicity of ivermectin on cladocerans: comparison of toxic effects on Daphnia and Ceriodaphnia species. Environ Toxicol Chem 28:2160-2166

Matha V, Weiser J (1988) Molluscicidal effect of ivermectin on Biomphalaria glabrata. J Invertebr Pathol 52:354-355

Moed JR, Hallegraeff GM (1978) Some problems in the estimation of chlorophyll-a and phaeopigments from pre- and post-acidification spectrophotometric measurements. Int Rev Gesamten Hydrobiol 63:787-800

Montforts MHMM, van Rijswick HF, de Haes HA (2004) Legal constraints in EU product labelling to mitigate the environmental risk of veterinary medicines at use. Regulat Toxicol Pharmacol 40:327-335

Nessel RJ, Wallace DH, Wehner TA, Tait WE, Gomez L (1989) Environmental fate of ivermectin in a cattle feedlot. Chemosphere 18:1531-1541

Sanderson H, Laird B, Pope L, Brain R, Wilson C, Johnson D, Bryning G, Peregrine AS, Boxall A, Solomon K (2007) Assessment of the environmental fate and effects of ivermectin in aquatic mesocosms. Aquat Toxicol 85:229-240

Spinosa HD, Stilck SRAN, Bernardi MM (2002) Possible anxiolytic effects of ivermectin in rats. Vet Res Commun 26:309-321

Taylor SM (1999) Sheep scab: environmental considerations of treatment with doramectin. Vet Parasitol 83:309-317

Tisler T, Kozuh Erzen N (2006) Abamectin in the aquatic environment. Ecotoxicology 15:495-502

Van den Brink PJ, Ter Braak CJF (1998) Multivariate analysis of stress in experimental ecosystems by Principal Response Curves and similarity analysis. Aquat Ecol 32:163-178

Van den Brink PJ, Ter Braak CJF (1999) Principal response curves: analysis of time-dependent multivariate responses of biological community to stress. Environ Toxicol Chem 18:138-148 
Van den Brink PJ, Van Donk E, Gylstra R, Crum SJH, Brock TCM (1995) Effects of chronic low concentrations of the pesticides chlorpyrifos and atrazine in indoor freshwater microcosms. Chemosphere 31:3181-3200

Van den Brink PJ, Van Wijngaarden RPA, Lucassen WGH, Brock TCM, Leeuwangh P (1996) Effects of the insecticide Dursban 4E (active ingredient chlorpyrifos) in outdoor experimental ditches: II. Invertebrate community responses and recovery. Environ Toxicol Chem 15:1143-1153

Van den Brink PJ, Tarazona JV, Solomon KR, Knacker T, Van den Brink NW, Brock TCM, Hoogland JP (2005) The use of terrestrial and aquatic microcosms and mesocosms for the ecological risk assessment of veterinary medicinal products. Environ Toxicol Chem 24:820-829

Van Wijngaarden RPA, Brock TCM, Douglas MT (2005) Effects of chlorpyrifos in freshwater model ecosystems: the influence of experimental conditions on ecotoxicological thresholds. Pest Manag Sci 61:923-935

Van Wijngaarden RPA, Brock TCM, van den Brink PJ, Gylstra R, Maund SJ (2006) Ecological effects of spring and late summer applications of lambda-cyhalothrin on freshwater microcosms. Arch Environ Contam Toxicol 50:220-239

Williams DA (1972) The comparison of several dose levels with zero dose control. Biometrics 28:519-531 